\title{
PROSPECT BUDIDAYA USAHA LEBAH MADU (Trigona $s p$ ) DENGAN METODE TOPING DAN STUP
}

\author{
Safrin Edy ${ }^{1}$, Ld Al Hemawan Ardi ${ }^{2}$ \\ Program Studi Agribisnis \\ Fakultas Pertanian \\ Universitas Muhammadiyah Buton \\ Jl. Betoambari No. 36 Baubau \\ E-mail: safrinediumb@gmail.com
}

\begin{abstract}
This study aims to analyze the feasibility of the business and analyze the opportunities and threats of Trigona Ongka farm in Laompo Village, Batauga District, South Buton Regency. The research was conducted from January to February 2020 in Laompo Village, Batauga District, South Buton Regency. The sample in this study was 1 (one) honeybee breeders (Trigona sp). The method used is the independent sample t-test and the $R / C$ feasibility analysis. Business opportunities and threats are analyzed qualitatively. The results showed that the business feasibility of Trigona sp honey bee livestock through the STUP and topping method was 1.5, $(R / C>1)$, meaning that each additional cost incurred resulted in a larger increase in revenue as much as IDR 1,400,000 for the STUP method and IDR 1,500,000 for the topping method instead of additional costs or simply profitable business activities. The honey bee livestock business opportunity of Trigona sp, namely honey as a favorite that is popular, relatively stable price, partially known production of the community, the location is easy to reach by vehicles, the availability of large land for business development. While the threat of Trigona sp honey bee livestock, namely: lack of environmental carrying capacity, so that environmental improvements and increasing the number of bee colonies are needed to increase honey production, do not have a product brand to be widely commercialized, product quality standardization is still poorly understood by breeders, there is no internal coordination between breeders to strengthen institutions and lack of access to assistance from capital institutions in terms of capital.
\end{abstract}

Keywords: Prospects, Business Feasibility, Honey Bees

\begin{abstract}
Abstrak
Tujuan penelitian ini adalah untuk menganalisis kelayakan usaha dan menganalisis peluang serta ancaman peternakan Trigona Ongka di Kelurahan Laompo Kecamatan Batauga Kabupaten Buton Selatan. Penelitian dilakukan pada bulan Januari sampai dengan bulan Februari 2020 di Kelurahan Laompo Kecamatan Batauga Kabupaten Buton Selatan. Sampel dalam penelitian ini adalah peternak lebah madu (Trigona sp) yang berjumlah 1 (satu) orang. Metode yang digunakan adalah uji beda rata-rata tidak berpasang (Independent sample t-test) dan analisis kelayakan R/C, Peluang dan ancaman usaha dianalisis secara kualitatif. Hasil penelitian menunjukan bahwa kelayakan usaha ternak lebah madu Trigona sp melalui metode stup dan topping sebesar 1,5, (R/C > 1) artinya setiap pertambahan biaya yang dikeluarkan menghasilkan pertambahan penerimaan yang lebih besar sebanyak Rp. 1.400.000 untuk metode stup dan Rp.1.500.000 untuk metode topping dari pada tambahan biaya atau secara sederhana kegiatan usaha menguntungkan. Peluang usaha ternak lebah madu Trigona $s p$ yaitu madu sebagai prodak unggulan yang digemari, harga relatif stabil, produksi sebagian telah dikenal Masyarakat, lokasi mudah dijangkau oleh kendaraan, tersedianya lahan yang
\end{abstract}


luas untuk pengembangan usaha. Sementara ancaman ternak lebah madu Trigona sp yaitu : kurang daya dukung lingkungan, sehingga diperlukan perbaikan lingkungan dan penambahan jumlah koloni lebah untuk meningkatkan produksi madu, belum memiliki merek prodak untuk dikomersilkan secara luas, standarisasi mutu produk masih kurang dipahami oleh peternak, belum adanya kordinasi intern antar peternak untuk menguatkan kelembagaan dan kurangnya akses bantuan lembaga permodalan dalam hal permodalan

Kata Kunci: Prospek, kelayakan usaha, lebah madu

\section{PENDAHULUAN}

\section{Latar Belakang}

Usaha peternakan lebah memiliki peluang yang sangat baik untuk dibudidayakan di masyarakat pedesaan, karena wilayah Indonesia memiliki potensi sumber daya alam hayati yang menunjang dalam pengembangan agribisnis, yaitu berupa berbagai jenis lebah, berbagai jenis tanaman sebagai sumber makanan bagi lebah. serta sumber getah dan kondisi lingkungan tropis yang sangat mendukung kelestarian alam dan pembangunan agrgibisni.

Beberapa jenis lebah yang baik untuk dibudidayakan salah satunya adalah jenis Trigona sp. Walaupun madu produksi tidak sebanyak keluarga lebah Apis sp, namun produksi propolis mentah (bahan propolis) cukup banyak. Metty (2017) menjelaskan bahwa Trigona sp/klulut/klanceng/teuweul merupakan kelompok serangga sosial yang hidup berkelompok untuk membuat koloni. Setiap koloni lebah memiliki antara 300 dan 80.000 lebah. Hingga 2017, 61 spesies telah diidentifikasi di Indonesia, 6 di antaranya berada di pulau Sulawesi. (Thomas dan Engel, 2017). Jenis-jenis Trigona sp sebagai berikut: a) Wallacetrigona incisa, b) Tetragonula biroi, c) Tetragonula clypearis, d) Tetragonula fuscobalteata, e) Tetragonula laeviceps, f) Tetragonula sapiens.

Kegiatan budidaya ternak lebah madu Trigona sp atau dalam Bahasa Buton disebut ongka belum banyak dibudidayakan yang salah satunya adalah di Kabupaten Buton Selatan. Hal ini berdasarkan fakta di lapangan bahwa produk dari lebah Trigona sp yang terdapat dipasaran masih tergolong sedikit. Sementara jika dilihat dari produk Trigona $s p$ seperti madu memiliki harga yang relatife lebih tinggi dibandingkan dengan madu yang di hasilkan dari kelompok Apis sp. Harga madu jenis lebah ini adalah berada diantara Rp. 90.000 sampai Rp. 130.000 setiap botol dengan ukuran 250 milliliter.

Kebutuhan madu yang setiap tahunnya selalu mengalami peningkatan maka usaha budidaya lebah Trigona sp sangatlah potensial untuk dilakukan. Potensi usaha budidaya ternak lebah dapat ditunjukkan dari data Asosiasi Perlebahan Indonesia (API) yang angka kebutuhan madu Indonesia berada antara 7.000 - 15.000 ton per tahun. Sementara Indonesia hanya mempu memproduksi madu baru mencapai 4.000 - 5.000 ton per tahun, artinya Indonesia belum memenuhi kebutuhan sebanyak 3.500-11.000 ton/tahun (Institusi Pertanian Bogor, 2019).

Pada era modern lebah Trigona $s p$ dibudidayakan dengan menggunakan Stup (peti lebah) dan Topping. Stup/peti lebah pertama ditemukan oleh ahli lebah Amerika Serikat, L.L. Langstroth pada tahun 1851. Stup harus dibuat dari bahan kayu dan tidak bisa terpengaruh oleh suhu udara, terutama pergantian dari musim panas kedingin atau sebaliknya, jenis ringan seperti kayu kemiri atau kayu lamtoro cocok untuk bahan petih lebah Trigona sp (Hendri, 2016). Stup memberikan kelebihan yang lebih baik disebabkan pemeliharaan lebah madu dalam stup akan memudakahkan pengelolaan dan pemanenannya 
tidak harus merusak sarang lebah. Sedangkan metode toping adalah salah satu metode budidaya sarang lebah trigona.

Metode topping adalah sarang lebah alami yang di tambah kotak kayu di bagian atas sebagai tempat madu. Kotak stup dan kotak topping dapat pakai dalam waktu yang cukup lama dan jangka waktu panen setiap kotak 3 (tiga) bulan untuk sekali panen, setiap metode memiliki keunggulan dan kekurangannya masing-masing, di peternakan lebah Trigona $s p$ Ongka Madu yang berada di Kabupaten Buton Selatan Kecamatan Batauga Kelurahan Laompo pada saat ini menggunakan ke 2 (dua) metode budidaya dalam pengembangan ternak lebah madu Trigona $s p$ yaitu metode stup dan metode topping. Sejauh ini peternak lebah madu Trigona sp di peternakan Ongka Madu belum mengetahui metode yang tepat untuk mendukung dan mempercepat produksi madu dalam budidaya lebah madu Trigona $s p$.

Selain itu peternak lebah belum mengetahui tingkat kelayakan usaha tersebut dan bagaimana peluang serta ancaman dari usaha yang dilakukan. Berdasarkan uraian latar belakang tersebut peneliti ingin mengkaji lebih mendalam bagaimana prospek usaha lebah madu yang ada di Kelurahan Laompo Kecamatan Batauga Kabupaten Buton Selatan.

\section{METODE PENELITIAN}

\section{Waktu dan Lokasi Penelitian}

Penelitian ini dilakukan pada rentan waktu Bulan Januari sampai dengan Bulan Februari 2020. Lokasi penelitian diKelurahan Laompo Kecamatan Batauga Kabupaten Buton Selatan dipeternakan lebah Trigona Ongka Madu. Penetapan lokasi penelitan dilakukan dengan pertimbangan karena lokasi tersebut merupakan lokasi yang mudah dijangkau peneliti, serta untuk meminimalisir biaya dalam penelitian.

\section{Populasi dan Sampel}

Populasi yaitu suatu wilayah yang terdapat suatu obyek atau subyek yang memiliki kualitas dan karakteristik tertentu yang ditentukan oleh peneliti untuk dicermati dan kemudian mengambil kesimpulannya (Sugiyono, 2005). Penelitian ini memiliki populasi peternak lebah madu Trigona sp dipeternakan ongka madu Kelurahan Laompo yang berjumlah 1 (satu) peternak.

Penelitian ini memiliki populasi tidak lebih dari 100 sehingga penentuan sampel dilakukan secara sensus dengan mengambil seluruhnya populasi sebagai sampel yaitu 1 (satu) peternak lebah madu Trigona $s p$ dipeternakan ongka madu Kelurahan Laompo. Hal ini disesuaikan dengan pendapat Arikunto (2008) jika subyek tidak lebih dari 100, maka subyek diambil semua sehingga pengambilan sampel dilakukan secara sensus, berikutnya jika subyek melebihi dari 100 maka dapat diambil 10-15\% atau 20-25\% atau lebih.

\section{Jenis dan Sumber Data}

\section{a. Jenis data}

Penelitian dibedakan menjadi dua cara ialah penelitian kuantitatif dan penelitian kualitatif. Penelitian Kuantitatif yaitu penelitian yang data penelitiannya berbentuk angkaangka dan dianalisis menggunakan statistika (Sugiyono, 2008). Penelitian kualitatif yaitu penelitian yang hasil dari data penelitian lebih bersinggungan dengan interpretasi terhadap data yang diperoleh di lapangan (Sugiyono, 2008). Penelitian kualitatif adalah suatu 
penelitian yang menerapkan cara ilmiah untuk mengungkapkan suatu kejadian dengan cara mendeskripsikan data dan fakta melalui perkataan secara menyeluruh terhadap subjek penelitian (Mulyana, 2008). Penelitian akan dilakukan dengan cara kualitatif.

\section{b. Sumber data}

Data primer merupakan data yang terpacu pada informasi yang didapat dari pihak pertama oleh seorang peneliti yang erat kaitannya dengan variabel minat untuk tujuan spesifik studi. Data primer bersumber dari kelompok fokus, responden individu, internet bisa menjadi sumber data primer jika koesioner penyebaran melalui internet (Uma, 2011). Selanjutnya ialaha data sekunder. Data sekunder merupakan data yang terpacu pada informasi yang diperoleh dari sumber yang sudah ada. Data sekunder diperoleh dari dokumentasi atau catatan perusahaan, publikasi pemerintah, situs Web, analisis industri oleh media, internet dan seterusnya (Uma, 2011). Data sekunder diperoleh dari kantor Kelurahan Laompo.

\section{Teknik Pengumpulan Data}

Penelitian kualitatif terdapat empat teknik dalam mengumpulkan data, teknik observasi adalah pemantauan dan pencatatan secara terpadu terhadap situasi yang nyata pada setiap objek penelitian (Zuriah, 2009). Wawancara yaitu teknik mendapatkan informasi dengan cara memberikan sejumlah pertanyaan secara lisan dan dijawab secara lisan pula (Zuriah, 2009). Triangulasi dapat katakan sebagai teknik mengumpulkan data yang tergabung dari berbagai teknik pengumpulan data dan informasi yang telah ada. Triangulasi seorang peneliti menerapkan teknik pengumpulan data yang berbeda-beda untuk memperoleh data dari sumber yang sama (Zuriah, 2009). Dokumentasi yaitu catatan peristiwa yang telah berlalu.

Dokumen bisa berupa gambar, karya-karya monumental dari seseorang atau tulisan. Studi dokumen bagian pelengkap dari penerapan metode observasi dan wawancara pada penelitian kualitatif (Sugiyono, 2008). Penelitian ini dilakukan dengan menggunakan dokumentasi.

Penelitian ini akan mengumpulkan data primer yang meliputi jumlah metode stup yang di terapkan, jumlah metode topping yang diterapkan, produksi madu dari setiap metode yang diterapkan, biaya produksi dari setiap metode, harga madu, pemeliharaan, pemanenan, biaya botol kemasan. Selanjutnya, data yang didapat dilapangan disajikan kedalam bentuk tabel kemudian dianalisis secara sistematik dan statistic kemudian sampaikan secara deskriptif, yaitu menampilkan data atau informasi yang didapat sehingga diperoleh hasil yang lengkap dan terinci.

\section{Variabel Penelitian}

Kelayakan usaha ternak madu yang meliputi : harga jual, biaya-biaya, produksi, penerimaan, pendapatan usaha. Prospek usaha usaha ternak madu yang meliputi : peluang dan ancaman usaha.

\section{Analisis Data}

a) Analisis kelayakan usaha

Mengalisis kelayakan usaha menggunakan statistik pendapatan (Soekartawi, 2002) yang di peroleh dari perhitungan sebagai berikut :

\section{Biaya Produksi : $\mathbf{T C}=\mathbf{T F C}+\mathbf{T V C}$}




\section{P-ISSN: 2527-8479 E-ISSN: 2686-2174}

Keterangan :

TC : Total Cost / Biaya Total (Rp);

TFC : Total Fixed Cost / Total Biaya Tetap (Rp);

TVC : Total Variabel Cost / Total Biaya Variabel $(\mathrm{Rp} / \mathrm{Kg})$.

2. Penerimaan kotor: $\mathbf{T R}=\mathbf{P} \cdot \mathbf{Q}$

Keterangan :

$\mathrm{TR}=$ Penerimaan kotor $(\mathrm{Rp})$

$\mathrm{P} \quad=$ Harga jual $(\mathrm{Rp} / \mathrm{Kg})$

$\mathrm{Q}=$ Jumlah produksi $(\mathrm{ml})$

3. Pendapatan bersih : JI = TR TC

Keterangan :

JI : Pendapatan (Rp);

TR : Total Revenue / Total Penerimaan kotor

(Rp); TC : Total Cost / Biaya Total (Rp);

Tingkat kelayakan usaha dianalisis melalui imbangan antara penerimaan total dengan biaya total yang disebut Return and Cost Ratio (R/C ratio). Menurut Soekartawi (2002) R/C rasio adalah total ratio yang digunakan untuk melihat keuntungan ideal yang didapatkan dalam sebuah dengan rumus :

$\mathrm{RC}$ ratio $: \mathrm{R} / \mathrm{C}=$ Penerimaan Total $(T R)$

Biaya Total $(T C)$

Kriteria :

R / C > 1, Hasil Usaha

Menguntungkan R / C = 1, Hasil

Usaha Seimbang

R / C $<1$, Hasil Usaha Rugi

b) Analisis deskripsi kualitatif untuk memaparkan atau menggambarkan prospek usaha lebah madu Trigona sp yang di usahakan baik peluang dan ancaman usaha yang dilakukan.

\section{HASIL DAN PEMBAHASAN}

\section{Gambaran Umum Daerah Penelitian}

Kelurahan Laompo merupakan salah satu kelurahan yang ada di Kecamatan Batauga Kabupaten Buton Selatan. Letak Kecamatan Batauga ditampilkan dari peta Kebupaten Buton Selatan berada di sebelah selatan Pulau Buton. Secara geografis terletak diantara $5,90^{\circ}-5,59^{\circ}$ LS. Kelurahan Laompo berada dalam wilayah ibu kota Kabupaten Buton Selatan dengan luas wilayahnya kurang lebih $933 \mathrm{~km}^{2}$.

Peternak lebah madu Trigona $s p$ memiliki usia 25 tahun, usia tersebut merupakan usia yang baik untuk melakukan usaha budidaya lebah madu dengan pengalaman 2 tahun dalam melakukan usaha budidaya lebah madu Trigona sp. Tingkat pendidikan peternak adalah SMA, meskipun tingkat pendidikan peternak hanya pada tingkat SMA tetapi pengetahuan peternak berada pada tingkat yang sesuai karena peternak menempuh pendidikan pada bidang keahlian kehutanan. Menurut Septriani, dkk (2007) pendidikan 


\section{P-ISSN: 2527-8479 E-ISSN: 2686-2174}

sangat berperan penting dalam usaha peternakan karena merupakan modal dasar dalam meningkatkan kemampuan dan pola piker peternak dalam menerima berbagai inovasi dan teknologi yang semakin berkembang. Jumlah Tanggungan keluarga peternak sebanyak adalah sebanyak 2 orang.

\section{Analisis Statistik Pendapatan}

a) Biaya Produksi

Biaya produksi pada usaha budidaya lebah madu Trigona sp pada penelitian ini adalah semua biaya yang dikeluarkan oleh peternak dalam satu kali produksi pada setiap metode budidaya yang di terapkan. Biaya Produksi dalam penelitian ini berupa biaya variabel dan biaya tetap:

1. Biaya Variabel

Tabel 1 Jumlah Biaya Variabel Antara Metode Stup dan Metode Topping dalam per Periode Panen.

\begin{tabular}{cccc}
\hline No. & \multicolumn{1}{c}{ Uraian } & Stup (Rp) & Topping (Rp) \\
\hline 1. & Pencarian Koloni & Rp. 100.000 & Rp. 200.000 \\
\hline 2. & Pemeliharaan & Rp. 20.000 & Rp. 20.000 \\
\hline 3. & Pemanenan & Rp. 10.000 & Rp. 10.000 \\
\hline 4. & Botol Kemasan & Rp. 33.600 & Rp. 42. 000 \\
\hline 5. & Tenaga Kerja & Rp. 240.000 & Rp. 300.000 \\
\hline & Jumlah & Rp. 403.600 & Rp. 572.000 \\
\hline
\end{tabular}

Tabel 1 menunjukan jumlah biaya variabel antara metode stup dan metode topping terdapat perbedaan jumlah biaya variabel yang harus dikeluarkan oleh peternak dalam per periode panen, pada tabel diatas total biaya variabel dengan menggunakan metode stup adalah Rp. 403.600 sedangkan total biaya variabel dengan menggunakan metode topping adalah Rp. 572.000.

2. Biaya Tetap

Tabel 2 Jumlah Biaya Tetap Antara Metode Stup dan Metode Topping dalam Per Periode Panen

\begin{tabular}{llcc}
\hline No. & \multicolumn{1}{c}{ Uraian } & Stup & Topping \\
\hline 1. & Pembuatan kotak & Rp. 305.000 & Rp. 270.000 \\
\hline 2. & Pajak tanah & Rp. 20.000 & Rp. 20.000 \\
\hline 3. & Penyusutan alat & Rp. 104.665 & Rp. 104.665 \\
\hline & Jumlah & Rp. $\mathbf{4 2 9 . 6 6 5}$ & Rp. 384.665 \\
\hline
\end{tabular}

Tabel 2 menunjukan jumlah biaya tetap antara metode stup dan metode topping 


\section{Media Agribisnis}

\section{Vol. 4, Issue 2, November 2020}

\section{P-ISSN: 2527-8479 E-ISSN: 2686-2174}

terdapat perbedaan jumlah biaya yang di keluarkan oleh peternak dalam per periode panen, pada tabel diatas total biaya tetap dengan menggunakan metode stup adalah Rp. 429.665 sedangkan total biaya tetap dengan menggunakan metode topping adalah Rp. 384.665.

3. Total Biaya Produksi

Tabel 3 Jumlah Biaya Produksi antara Metode Stup dan Metode Topping dalam Per Perode Panen

\begin{tabular}{llcc}
\hline No. & Jenis Biaya & Stup & Topping \\
\hline 1. & Biaya Variabel & Rp. 403.600 & Rp. 572.000 \\
2. & Biaya Tetap & Rp. 429.665 & Rp. 384.665 \\
\hline & Jumlah & Rp. 833.265 & Rp. 956.665 \\
\hline
\end{tabular}

Tabel 3 menunjukan total biaya produksi yang dikeluarkan oleh peternak per periode panen antara metode stup dan metode topping dapat dilihat pada tabel diatas yang menunjukan total biaya produksi untuk menggunakan metode stup adalah Rp. 833.265 per periode panen sedangkan total biaya produksi untuk menggunakan metode topping adalah Rp. 956.665 per periode panen.

b) Pendapatan Peternak

\section{Penerimaan Kotor}

Tabel 4 Penerimaan Kotor Peternak antara Metode Stup dan Metode Topping dalam per Periode panen

\begin{tabular}{lllcl}
\hline No. & Metode & Harga Jual/ Botol & $\begin{array}{c}\text { Total Produksi } \\
\text { Madu }\end{array}$ & $\begin{array}{c}\text { Penerimaan / } \\
\text { Periode Panen }\end{array}$ \\
\hline 1. & Stup & Rp. 100.000 & $3160 \mathrm{ml} / 250 \mathrm{ml}$ & Rp. 1.200 .000 \\
2. & Topping & Rp. 100.000 & $3980 \mathrm{ml} / 250 \mathrm{ml}$ & Rp. 1.500 .000
\end{tabular}

Tabel 4 menunjukan penerimaan kotor peternak antara metode stup dan metode topping terdapat perbedaan penerimaan yang diperoleh peternak. Pada tabel diatas penerimaan peternak dengan menggunakan metode stup adalah Rp. 1.200 .000 berbeda dengan penerimaan peternak dengan menggunakan metode topping sebesar Rp. 1.500.000. Pada tabel 4 harga jual per botol madu adalah Rp. 100.000 dan total produksi metode stup adalah $3160 \mathrm{ml}$ dan metode topping $3980 \mathrm{ml}$ yang dibagi dengan ukuran botol kemasan dengan ukuran botol kemasan $250 \mathrm{ml}$. Perbedaan penerimaan peternak disebabkan oleh perbedaan total produksi madu yang didapat oleh setiap metode.

\section{Pendapatan Bersih}

Tabel 5 Pendapatan Bersih Peternak pada Metode Stup dan Metode Topping dalam satu kali panen.

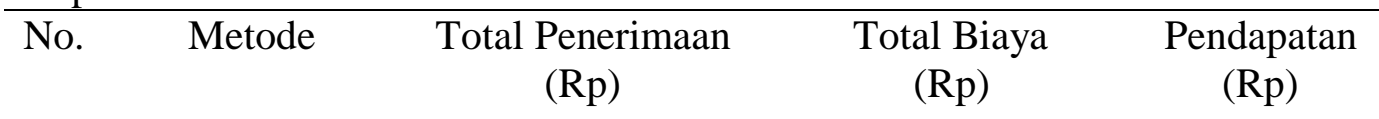




\section{P-ISSN: 2527-8479 E-ISSN: 2686-2174}

\begin{tabular}{lllll}
\hline 1. & Stup & Rp. 1.200 .000 & Rp. 833.265 & Rp. 366.735 \\
2. & Topping & Rp. 1.500 .000 & Rp. 956.665 & Rp. 543.335
\end{tabular}

Tabel 5 menunjukan pendapatan peternak lebah madu Trigona sp jenis Tetragonula biroi dengan menggunakan metode stup dan metode topping terdapat perbedaan pendapatan yang di peroleh peternak yaitu Rp. 366.735 untuk pendapatan metode stup dan Rp. 543.335 untuk pendapatan dengan menggunakan metode topping. Perbedaan pendapatan antara metode stup dan metode topping ini di sebabkan oleh jumlah produksi yang dihasilkan oleh metode topping lebih banyak yaitu $3980 \mathrm{ml}$ di bandingkan dengan jumlah produksi yang dihasilkan oleh metode stup yang lebih sedikit yaitu $3160 \mathrm{ml}$ meskipun metode topping membutuhkan biaya lebih banyak yaitu Rp. 956.665 dibandingkan dengan menggunakan metode stup yang membutuhkan biaya lebih sedikit yaitu Rp. 833.265.

c) $\quad \mathrm{R} / \mathrm{C}$ Ratio

Tabel 6 Analisis Ratio Metode Stup dan Metode Topping per Periode Panen

\begin{tabular}{llllc}
\hline No. & Metode & $\begin{array}{c}\text { Total Penerimaan } \\
(\mathrm{Rp})\end{array}$ & $\begin{array}{c}\text { Total Biaya } \\
(\mathrm{Rp})\end{array}$ & $\begin{array}{c}\text { R/C } \\
\text { Ratio }\end{array}$ \\
\hline 1. & Stup & Rp. 1.200 .000 & Rp. 833.265 & 1,4 \\
2. & Topping & Rp. 1.500 .000 & Rp. 956.665 & 1,5 \\
\hline
\end{tabular}

Efefesien dalam penggunaan biaya pada metode stup dan metode topping,dapat di katakana layak apabila $\mathrm{R} / \mathrm{C}>1$, jika $\mathrm{R} / \mathrm{C}=1$ yang berarti penggunaan biaya seimbang, dan jika $\mathrm{R} / \mathrm{C}<1$ berarti penggunaan biaya tidak efisien atau boros. Pada tabel di atas, hasil analisis R / C rasio untuk metode stup adalah sebesar 1,4 dan rasio analisis R / C untuk metode topping adalah sebesar 1,5, sehingga dapat dikatakan bahwa penerapan metode dan metode stup dapat diabaikan, karena tingkat kelayakan $\mathrm{R} / \mathrm{C}$ ratio $>1$.

Menurut Marrisa (2010), tingkat pendapatan usaha dapat diukur melalui analisis pendapatan dan biaya ( $\mathrm{R}$ / C Ratio) yang dilakukan dalam perhitungan keuangan. Analisis ini menunjukkan tingkat penerimaan komersial yang akan diperoleh petani untuk setiap rupee biaya yang dikeluarkan untuk setiap kegiatan komersial. Jika R / C ratio lebih besar dari 1 atau $\mathrm{R} / \mathrm{C}>1$. Hal menunjukkan bahwa setiap pertambahan biaya yang dikeluarkan akan menghasilkan pertambahan penerimaan yang lebih besar sebanyak Rp. 1.400 .000 untuk metode stup dan Rp.1.500.000 untuk metode topping dari pada tambahan biaya atau secara sederhana kegiatan usaha budidaya madu ini menguntungkan. Sedangkan apabil nilai R/C Ratio lebih kecil dari $1(\mathrm{R} / \mathrm{C}<1)$ artinya pertambahan biaya yang dikeluarkan menghasilkan pertambahan penerimaan yang lebih kecil dibandingkan pertambahan biaya atau secara sederhana usaha dikatakan tidak menguntungkan atau merugi.

\section{Peluang dan Ancaman Usaha Peternakan Lebah Madu}

Berdasarkan hasil penelitian diketahui bahwa peluang dan ancaman dalam kegiatan usaha ternak lebah madu di Kelurahan Laompo dapat di sajikan menjadi beberapa bagian yang meliputi : 


\section{Media Agribisnis}

Vol. 4, Issue 2, November 2020

\section{P-ISSN: 2527-8479 E-ISSN: 2686-2174}

\section{Peluang Usaha Peternakan Lebah Madu}

Peluang usaha ternak lebah madu Kelurahan Laompo sebagai berikut :

1. Madu sebagai prodak unggulan yang di gemari

2. Harga relatif stabil

3. Produksi sebagian telah dikenal masyarakat

4. Lokasi mudah dijangkau oleh kendaraan

5. Tersedianya lahan yang luas untuk pengembangan peternakan

\section{Ancaman Usaha Peternakan Lebah Madu}

Sedangkan dari sisi ancaman bagi pelaku usaha ternak lebah madu Kelurahan Laompo sebagai berikut :

1. Kurang daya dukung lingkungan, sehingga diperlukan perbaikan lingkungan dan penambahan jumlah koloni lebah untuk meningkatkan produksi madu.

2. Belum memiliki merek prodak untuk dikomersilkan secara luas

3. Standarisasi mutu produk masih kurang dipahami oleh peternak

4. Belum adanya kordinasi intern antar peternak untuk menguatkan kelembagaan

5. Kurangnya akses bantuan lembaga permodalan dalam hal permodalan

Sehingga berdasarkan asumsi tersebut dapat di rekomendasikan dalam penelian ini mengenai prospek jangka panjang pengembangan lebah madu Trigona sp sebagai berikut ;

1. Peningkatan produksi melalui peningkatan introduksi teknologi budidaya secara intensif dan berwawasan lingkungan.

2. Mengubah pola pengelolaan dengan sistem manajemen yang baik, peningkatan ketrampilan melalui pelatihan budidaya yang ramah lingkungan.

3. Pemberian bantuan dari permodalan usaha dengan kredit lunak bagi peternak lebah sehingga dapat mengembangkan usahanya yaitu dengan meningkatkan produksi madu secara maksimal.

\section{KESIMPULAN DAN SARAN}

\section{Kesimpulan}

Berdasarkan hasil analisis data dan pembahasan, peneliti menyimpulkan beberapa hal sebagai berikut :

1. Tingkat kelayakan usaha ternak lebah madu Trigona sp melalui metode stup dan topping sebesar $1,5,(\mathrm{R} / \mathrm{C}>1)$ artinya setiap pertambahan biaya yang dikeluarkan menghasilkan pertambahan penerimaan yang lebih besar sebanyak Rp. 1.400 .000 untuk metode stup dan Rp.1.500.000 untuk metode topping dari pada tambahan biaya atau secara sederhana kegiatan usaha menguntungkan.

2. Peluang usaha ternak lebah madu Trigona $s p$ yaitu madu sebagai prodak unggulan yang digemari, harga relatif stabil, produksi sebagian telah dikenal Masyarakat, lokasi mudah dijangkau oleh kendaraan, tersedianya lahan yang luas untuk pengembangan usaha. Sementara ancaman ternak lebah madu Trigona sp yaitu : kurang daya dukung lingkungan, sehingga diperlukan perbaikan lingkungan dan penambahan jumlah koloni lebah untuk meningkatkan produksi madu, belum memiliki merek prodak untuk dikomersilkan secara luas, standarisasi mutu produk masih kurang dipahami oleh peternak, belum adanya kordinasi intern antar peternak untuk menguatkan kelembagaan dan kurangnya akses bantuan lembaga permodalan dalam hal 


\section{P-ISSN: 2527-8479 E-ISSN: 2686-2174}

permodalan

\section{Saran}

Saran dari peneliti adalah:

a. Peternak lebah madu Trigona sp jenis Tetragonula biroi dapat menggunakan metode topping untuk memperoleh hasil produksi yang maksimal.

b. Perlu memberikan merek prodak untuk dikomersilkan secara luas dan standarisasi mutu produk agar dapat bersaing dengan produk sejinis dipasarsan.

c. Perlu pendampingan dari pemerintah dan stakeholder untuk pengembangan usaha yang dilakukan oleh masyarakat UMKM.

\section{DAFTAR PUSTAKA}

Arikunto, Suharsimi. 2006. Metodologi Penelitian. Yogyakarta : Bina Aksara

Hendri Banowu. 2016. Studi Pengembangan Koloni dan Produksi Lebah (Trigona sp) Dari Posisi Stup Berbeda. Fakultas Kehutanan dan Ilmu Lingkungan Universitas Halu Oleo. Skripsi.

Institusi Pertanian Bogor. 2019. Fakultas Pertanian. Prospek Agribisnis Lebah Madu. Bogor.

Istana Klanceng. 2017. Teknologi Budidaya Klanceng Sistem Topping. peternak lebah klanceng dan peneliti metode pembibitan klanceng. Probolinggo.

Jennifer C. Thomas, and Michael S. Engel. 2017. A New Genus of Eastern Hemisphere Stingless Bees (Hymenoptera: Apidae), with a Key to the Supraspecific Groups of Indomalayan and Australasian Meliponini. American Museum Novitates.

Metty Lasmayanty. 2017. Potensi Anti Bakteri Propolis Lebah Madu (Trigona sp) Terhadap Bakteri Kariogenik (Streptococcus mutans). Fakultas Matematika dan Ilmu Pengetahuan Alam Institusi Pertanian Bogor. Skripsi.

Mulyana, Deddy. 2008. Komunikasi efektif "Suatu pendekatan lintas budaya. Bandung : PT Remaja Rosdakarya.

Saptiarni. F.H.T., B. Guntoro., E. Sulastri. 2007. Tingkat Partisipasi Anggota Kelompok Tani Ternak Pandakan Mulyo Srandakan Batul. Media peternakan.

Soekartawi. 2002. Analisis Usahatani.Jakarta: Universitas Indonesia. Jakarta

Uma. 2011. Research Methods For Business (Metode Penelitian Untuk Bisnis). Jakarta: Salemba Empat. 